\title{
EVOLUTION OF NASA'S NEAR-EARTH TRACKING AND DATA RELAY SATELLITE SYSTEM (TDRSS)
}

\section{Roger Flaherty -- Deputy Program Manager, Space Communications ${ }^{1}$; Frank Stocklin ${ }^{1}$; Aaron Weinberg ${ }^{2}$}

\section{NASA Goddard Space Flight Center \\ 2. ITT Industries, Advanced Engineering and Sciences}

\section{Section 1: Introduction}

NASA's Tracking and Data Relay Satellite System (TDRSS) is now in its $23^{\text {rd }}$ year of operations and its spacecraft fleet includes three second-generation spacecraft launched since the year 2000; Figure 1 illustrates the first generation TDRSS spacecraft. During this time frame the TDRSS has provided communications relay support to a broad range of missions, with emphasis on low-earth-orbiting (LEO) spacecraft that include unmanned science spacecraft (e.g., Hubble Space Telescope), and human spaceflight (Space Shuttle and Space Station). Furthermore, the TDRSS has consistently demonstrated its uniqueness and adaptability in several ways. First, its S- and K-band services, combined with its multi-band/steerable single-access (SA) antennas and ground-based configuration flexibility, have permitted the mission set to expand to unique users such as scientific balloons and launch vehicles. Second, the bent-pipe nature of the system has enabled the introduction of new/improved services via technology insertion and upgrades at each of the ground terminals; a specific example here is the Demand Access Service (DAS), which, for example, is currently providing science-alert support to NASA science missions Third, the bent-pipe nature of the system, combined with the flexible ground-terminal signal processing architecture has permitted the demonstration/validation of new techniques/services/technologies via a real satellite channel; over the past $10^{+}$years these have, for example, included demonstrations/evaluations of emerging modulation/coding techniques.

Given NASA's emerging Exploration plans, with missions beginning later this decade and expanding for decades to come, NASA is currently planning the development of a seamless, NASA-wide architecture that must accommodate missions from near-earth to deep space. Near-earth elements include GroundNetwork (GN) and Near-Earth Relay (NER) components and both must efficiently and seamlessly support missions that encompass: earth orbit, including dedicated science missions and lunar support/cargo vehicles; earth/moon transit; lunar in-situ operations; and other missions within 2 million $\mathrm{km}$ of earth (e.g., at the sun/earth libration points). Given that the NER is an evolution of TDRSS, one element of this NASA-wide architecture development activity is a trade study of future NER architecture candidates. The present paper focuses on trade study aspects associated with the NER, highlights study elements, and provides representative interim results. 
Figure 1: First Generation TDRSS Satellite

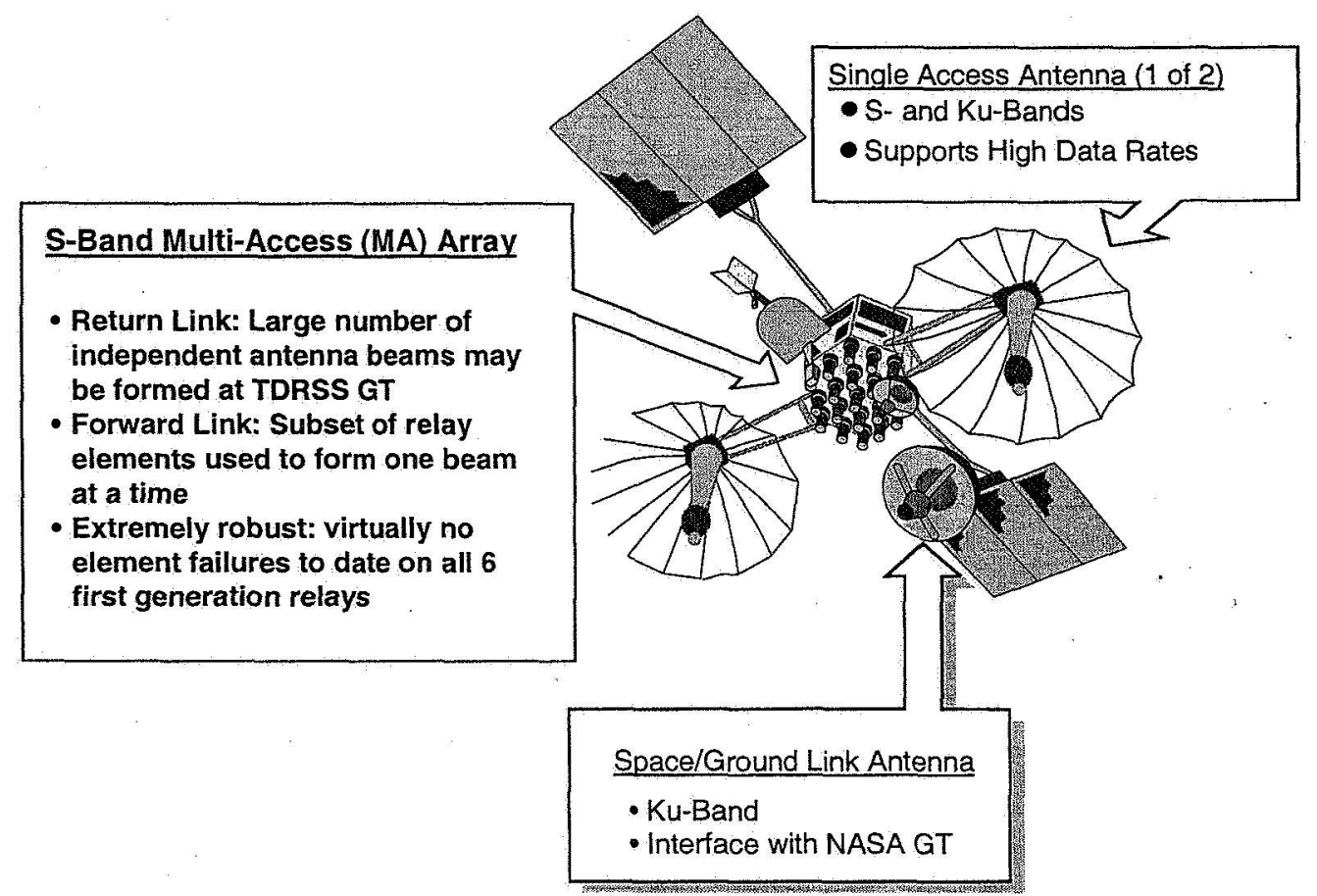

11/199/96 K:PPT_TB962461AW9380

\section{Section 2: Trade Study Elements and Approach}

Figure 2 provides a top-level description of the NER element, including the principal spacesegment/ground segment functions and interfaces. It should be noted that the specific relay constellation and ground segment characteristics -- including orbits, quantity, locations, connectivity, and detailed functionality -- are not explicitly addressed here. Instead, these are derived via technical/cost trades, based on specific assumptions and analysis applied to a range of architecture options, as discussed below. Key inputs to the technical/cost trades, and related consideration, include:

- Anticipated, high-level NER functional and performance capabilities (e.g., coverage, data rates), as derived from potential high-level Exploration and Near-Earth requirements (Table 1). This is used as a framework for establishing a constellation and the services provided.

- Definitions of a candidate range of space/ground architectures and high-level operations concepts that embody the above capabilities. The relay constellations addressed here are circular in nature and span GEO, MEO, and lower orbits. Specific assumptions and criteria are employed -- described below -- to ensure that mutually consistent, "apples-to-apples" comparisons may be suitably executed.

- Comparative assessment results are provided that address relative space-segment/ground-segment costs, as well as a set of Figures of Merit (FOMs), such as Transition and Operational Complexity 


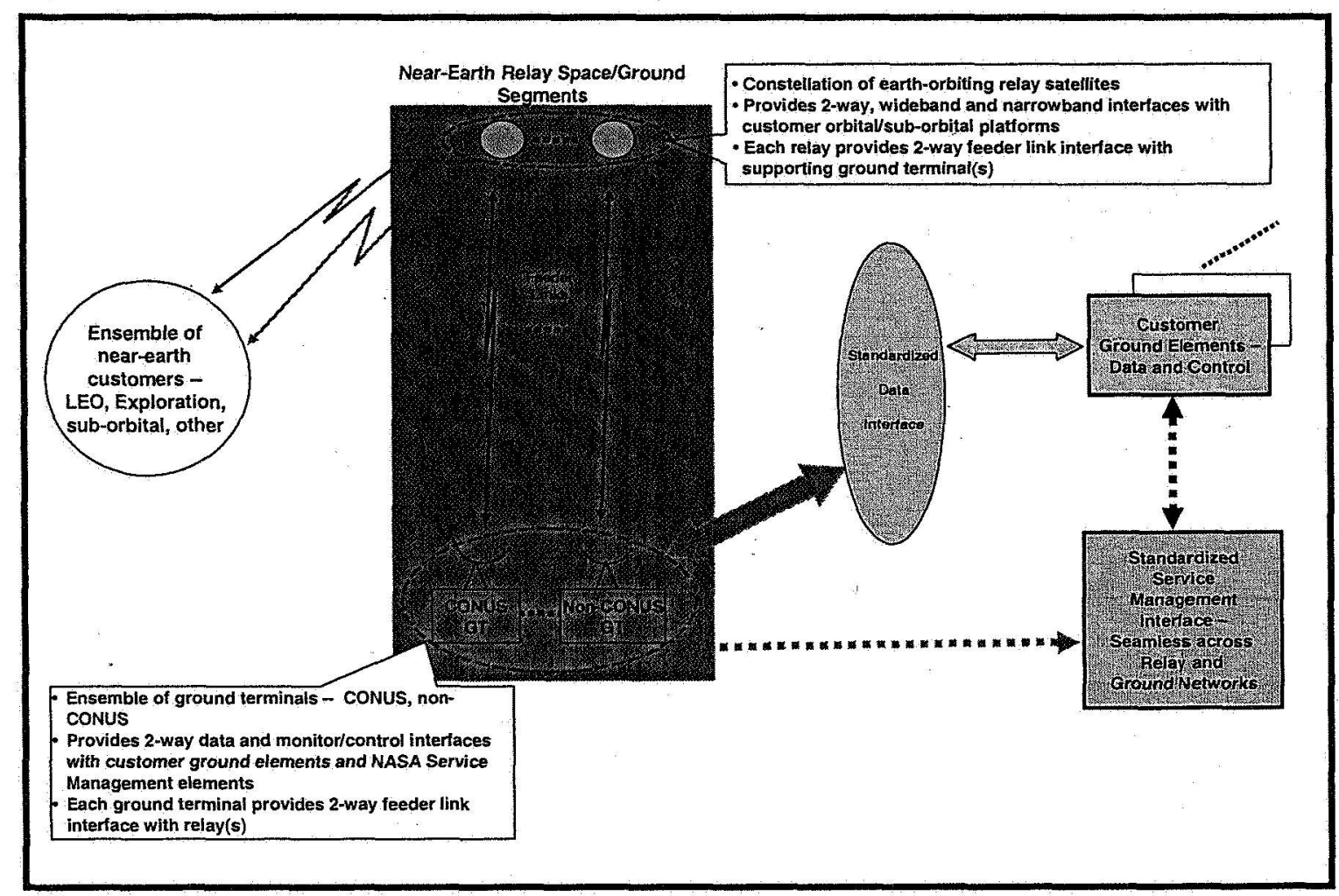

Figure 2: Near-Earth Element (NER) Overview

\section{Section 3: Architecture Options Considered}

As Figure 3 illustrates, a broad range of competing considerations present themselves, and no single NER space/ground architecture optimally satisfies the ensemble of all constraints. For example, the GEO relay offers maximum heritage, reduced transition complexity, and operational simplicity (due to the static nature of the space/ground interface). On the other hand, lower relay orbits offer reduced spacecraft mass and per-relay launch cost for a given level of user link burden. As such, the need arises to identify and address a sufficiently complete, discrete set of architectures that:

- permits a comprehensive and credible comparative technical/cost assessment across key constraints of interest; and

- avoids the need for a set to be so large as to preclude a timely assessment process

Toward this end, a range of architecture options was identified, that reflect relay constellation options spanning circular GEO, MEO, and LEO orbits. The option set is shown in Table 2, and high-level architectural topologies are illustrated in Figures $4-6$ for a GEO and 2 MEO candidates. The following should be noted:

- Implicit is the result of supporting analysis, that was conducted to establish viable space/ground segment topologies, quantities and implementations. 
- The range of options reflect uniform, key system parameter values relating to narrowband/wideband user services, coverage, capacity, and user burden, so that mutually consistent, "apples-to-apples" comparisons could be made. For example, the baseline GEO architecture in Figure 4 reflects an evolution of the current TDRSS, with Atlantic, Pacific, Indian Ocean nodes and 2 geographically distributed ground sites (one in CONUS, one outside of CONUS). The MEO $1 / 2$ sync constellation offers essentially the same global coverage (Figure 7), and has aperture sizes scaled to provide comparable user link burden; in addition, each of the six relays has one Single Access (SA) aperture (as opposed to two for each GEO), so that the two constellations offer the same on-orbit capacity.

- Note also that lower orbiting constellations necessarily offer more on-orbit SA aperture capacity, but this is required in order to ensure that all relays are identical and to further ensure the same global coverage capability.

Table 1: Key NER Functional Requirements

\begin{tabular}{|c|c|}
\hline NER Requirement & Key Drivers/Considerations \\
\hline $\begin{array}{l}\text { Provide real-time relay of user data between } \\
\text { user platform and its ground facility(ies) }\end{array}$ & $\begin{array}{l}\text { Highly-limited, or non-existent, line-of-sight visibility from } \\
\text { ground stations }\end{array}$ \\
\hline $\begin{array}{l}\text { Provide global coverage: to surface (latitudes } \\
\text { to } \sim 70^{\circ} \text { ); to altitudes up to } \geq 30 \mathrm{~K} \mathrm{~km}\end{array}$ & $\begin{array}{l}\text { Continuous communications support to CEV and other lunar } \\
\text { vehicles during flight phases not accommodated by Ground } \\
\text { Network } \\
\text { - Must accommodate certain } 24 \times 7 \text {, on demand Services } \\
\text { - Enable near-global operations capability for sub-orbital } \\
\text { missions (e.g. launch vehicles; balloons) }\end{array}$ \\
\hline $\begin{array}{l}\text { Provide scheduled telecommunication } \\
\text { services }\end{array}$ & $\begin{array}{l}\text { Cost, complexity limits quantity of certain high-performance } \\
\text { space-relay resources, relative to size of user population; thus, } \\
\text { scheduling required to allocate limited resources }\end{array}$ \\
\hline $\begin{array}{l}\text { Provide } 24 \times 7 \text {, on-demand } \\
\text { telecommunication services }\end{array}$ & $\begin{array}{l}\text { - Science alerts (e.g., gamma ray bursts); E911 } \\
\text { - Housekeeping broadcasts, acknowledgements (e.g., via } \\
\text { Beacons broadcast) } \\
\text { - Candidate frequency band - S-band }\end{array}$ \\
\hline $\begin{array}{l}\text { Provide narrowband (e.g., TT\&C) } \\
\text { telecommunication services }\end{array}$ & User housekeeping \\
\hline $\begin{array}{l}\text { Provide wideband telecommunication } \\
\text { services -- }\end{array}$ & $\begin{array}{l}\text { Wideband mission data (e.g., to } 1 \mathrm{Gbps} \text { or higher, to support } \\
\text { advanced science instruments) } \\
\text { - HDTV } \\
\text { - Candidate frequency bands - Ku, } \mathrm{Ka} \text {, optical }\end{array}$ \\
\hline $\begin{array}{l}\text { Provide tracking services -- radiometric data } \\
\text { via communication links }\end{array}$ & $\begin{array}{l}\text { - GPS not-cost-effective for all users } \\
\text { - GPS not available or insufficient for user altitudes near and } \\
\text { beyond GEO }\end{array}$ \\
\hline Provide users with operational flexibility & $\begin{array}{l}\text { Diverse user set, with diverse requirements } \\
\text { - Signaling, waveform flexibility needed for various mission } \\
\text { phases } \\
\text { - Long-life of NER relays imposes need on relays to } \\
\text { accommodate degree of unanticipated evolution of user needs } \\
\text { - Considerations: bent-pipe relays; programmable ground } \\
\text { equipment }\end{array}$ \\
\hline
\end{tabular}


- Increasing number of relays

- Increasing number of GT's and/or need for inter-relay xlinks

- Increasing network operational complexity - e.g., user/relay and relay/ground handovers, bookkeeping

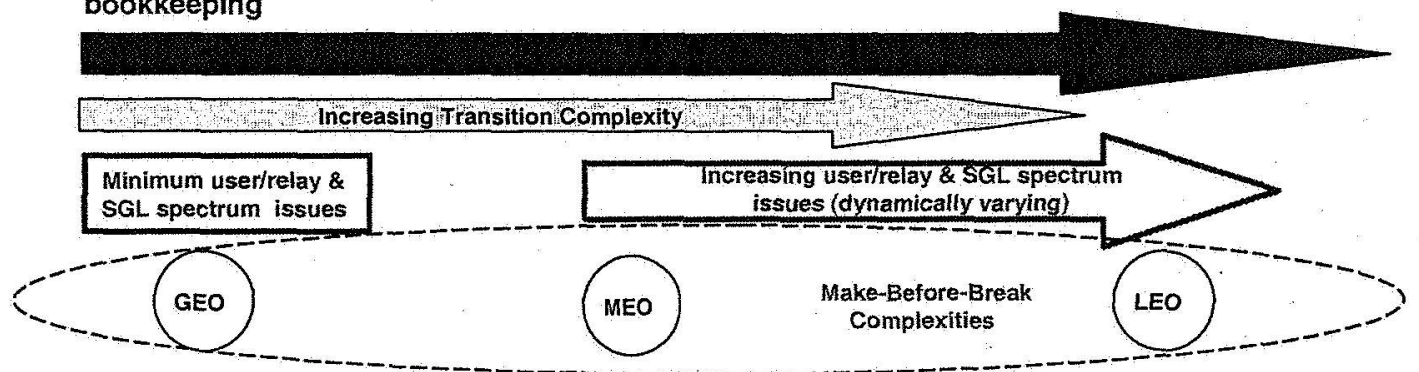

- Increasing relay aperture size for given user burden

- Increasing latency between user and GT via relay (no xlink); acceptable latency

for all orbits up to GEO

- Increasing launch vehicle size required for single relay launch

Figure 3: Architecture Trade Space and Considerations

Detailed trades across these options -- e.g, with/without crosslinks and with/without on-board processing -- and supporting technical/cost assessments were conducted.

\section{Figure 4: Notional GEO Architecture}

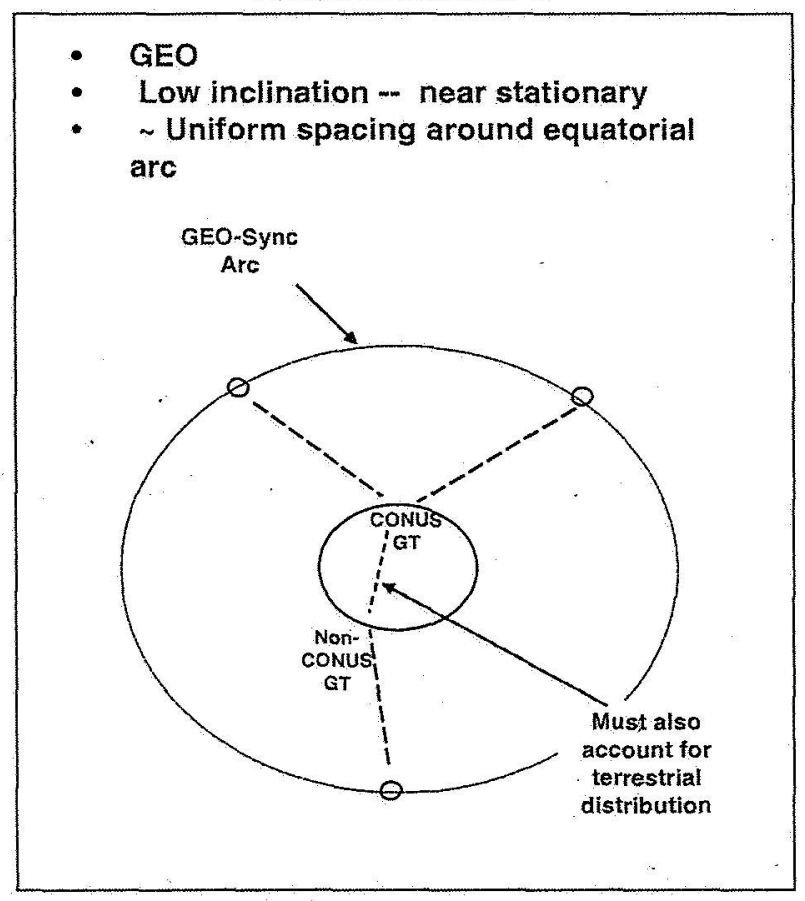

Figure 5: Notional MEO, $1 / 2$ Sync, Non-Crosslink Architecture

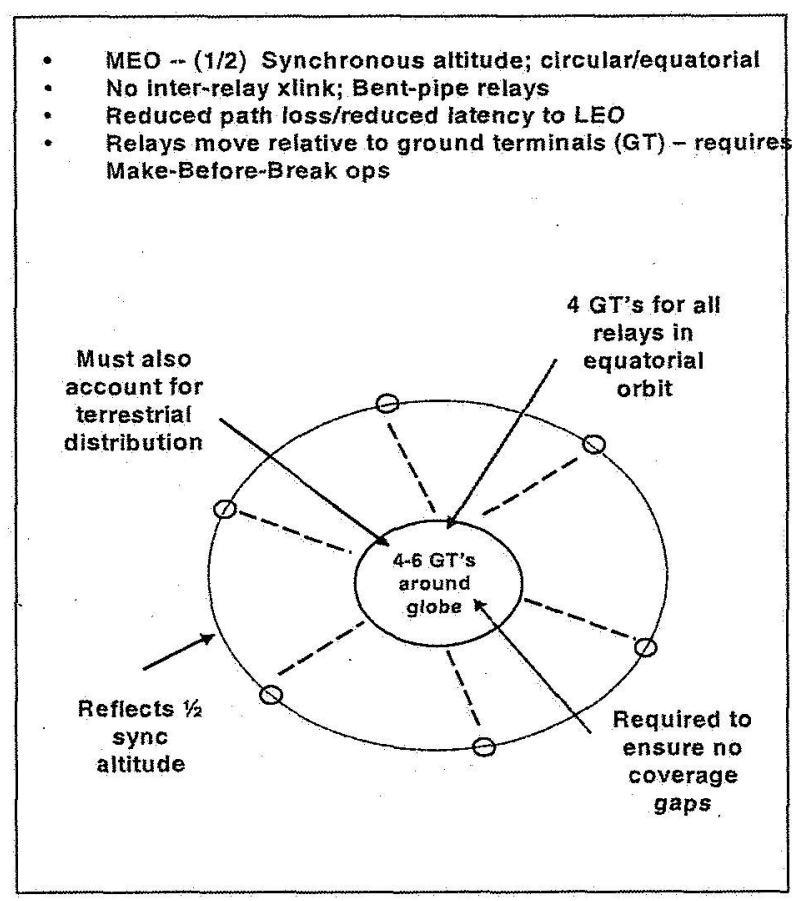


Figure 6:Notional MEO, $1 / 2$ Sync, Crosslink Architecture
MEO - (1/2) Synchronous altitudex circular/equatorial

Dual, inter-relay xlink per relay

Reduced path loss to LEO

Xlink increases latency relative to non-xlink case

Relays move relative to ground terminals (GT) - requires

Make-Before-Break ops

Xlink criticality increases ops/availability/ coverage risk

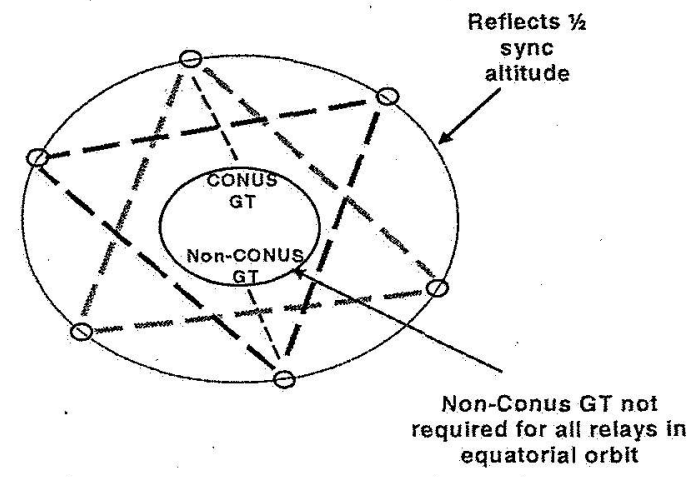

Table 2: Specific Architecture Options Evaluated

\begin{tabular}{|c|c|c|c|c|}
\hline $\begin{array}{c}\text { Constellation } \\
\text { (excluding spares) }\end{array}$ & $\begin{array}{l}\text { Quantity of } \\
\text { Relays }\end{array}$ & $\begin{array}{c}\text { Inter-Relay } \\
\text { Xlink }\end{array}$ & $\begin{array}{c}\text { User Burden } \\
\text { Considerations }\end{array}$ & $\begin{array}{c}\text { \#Ground Station } \\
\text { Locations }\end{array}$ \\
\hline $\begin{array}{l}\text { - GEO } \\
\text { - Equatorial }\end{array}$ & $3+1$ spare & No & $\begin{array}{l}\text { Nominal } \\
-3.5 \mathrm{~dB} \text { reduction }\end{array}$ & $2-1$ CONUS; 1 US OCONUS \\
\hline $\begin{array}{l}\text { MEO1 } \\
1 / 2 \text { Synchronous } \\
-20 \mathrm{k} \mathrm{km} \text { altitude } \\
\text { Equatorial }\end{array}$ & $6+1$ spare & No & $\begin{array}{l}\text { - Nominal } \\
\text { - } 3.5 \mathrm{~dB} \text { reduction }\end{array}$ & $\begin{array}{l}4-1 \text { CONUS; } 1 \text { US OCONUS; } \\
2 \text { non-US OCONUS }\end{array}$ \\
\hline $\begin{array}{l}\text { MEO1 } \\
\text { 1/2 Synchronous } \\
-20 \mathrm{~km} \text { altitude } \\
\text { - Equatorial }\end{array}$ & $6+1$ spare & $\begin{array}{l}\text { "Yes } \\
\text { " RF, bent-pipe; or } \\
\text { optical, OBP }\end{array}$ & Nominal & $1-$ CONUS \\
\hline $\begin{array}{l}\text { MEO; } 1 / 4 \text { Sync } \\
\text { Equatorial }\end{array}$ & $7+1$ spare & No & Nominal & $\begin{array}{l}\text { 4- } 1 \text { CONUS; } \\
3 \text { non-US OCONUS }\end{array}$ \\
\hline $\begin{array}{l}\text { - MEO; } 1 / 4 \text { Sync } \\
\text { - } 2 \text { planes } @ 70^{\circ} \text { inclination; } \\
\text { - } 4 \text { relays per plane }\end{array}$ & $\begin{array}{l}8+1 \text { spare per } \\
\text { plane }\end{array}$ & Yes & Nominal & $\begin{array}{l}3-1 \text { CONUS; } \\
2 \text { non-US OCONUS }\end{array}$ \\
\hline $\begin{array}{l}\text { - } 1 / 7 \text { Sync } \\
.2 \text { planes } 90^{\circ} \text { inclination; } \\
\text {. } 6 \text { relays per plane }\end{array}$ & $\begin{array}{l}12+1 \text { spare } \\
\text { per plane }\end{array}$ & Yes & Nominal & $\begin{array}{l}4-1 \text { CONUS; } 1 \text { US OCONUS; } \\
2 \text { non-US OCONUS }\end{array}$ \\
\hline $\begin{array}{l}\text { - } 1000 \mathrm{~km} \text { altitude } \\
\text {. } 5 \text { planes @ } 90^{\circ} \text { inclination; } \\
\text { 9 relays per plane }\end{array}$ & $\begin{array}{l}45+1 \text { spare } \\
\text { per plane }\end{array}$ & Yes & $16 \mathrm{~dB}$ reduction & $\begin{array}{l}>16 \text { globally distributed } \\
\text { ground stations }\end{array}$ \\
\hline
\end{tabular}

\section{Section 4: Detailed Evaluations}

For each architecture considered, the space and ground segments were addressed in much greater detail, and accounted for the following:

- Detailed functional space segment characterizations -- to levels permitting mass/power sizing, leading to non-recurring/recurring cost estimation. Notional GEO and MEO relay spacecraft descriptions -- which illustrate their antenna complements -- are shown in Figure 8, and serve as the starting points for the detailed internal configurations and sizing. Note that MEO service antenna 
aperture sizes are scaled to reflect the reduced user-to-relay and ground-terminal-to-relay slant ranges.

- Detailed functional ground segment characterizations -- to levels permitting hardware and software sizing -- leading to non-recurring/recurring cost estimation. Notional ground segment topologies and antenna complements are illustrated in Figure 9, with each Space/Ground Link Terminal (SGLT) servicing a single relay at a time.' Note that these figures explicitly address the make-before-break operational requirements of the non-GEO architectures, geographical distributions (corresponding to Table 2 above), and related operational aspects such as terrestrial distribution. The detailed sizing explicitly addresses internal functionality, sparing, and other aspects, such as emergency S-band TT\&C.

Figure 7: GEO (red) and MEO $1 / 2$ Sync (black) Earth Surface Coverage $\left(5^{0}\right.$ min elevation)

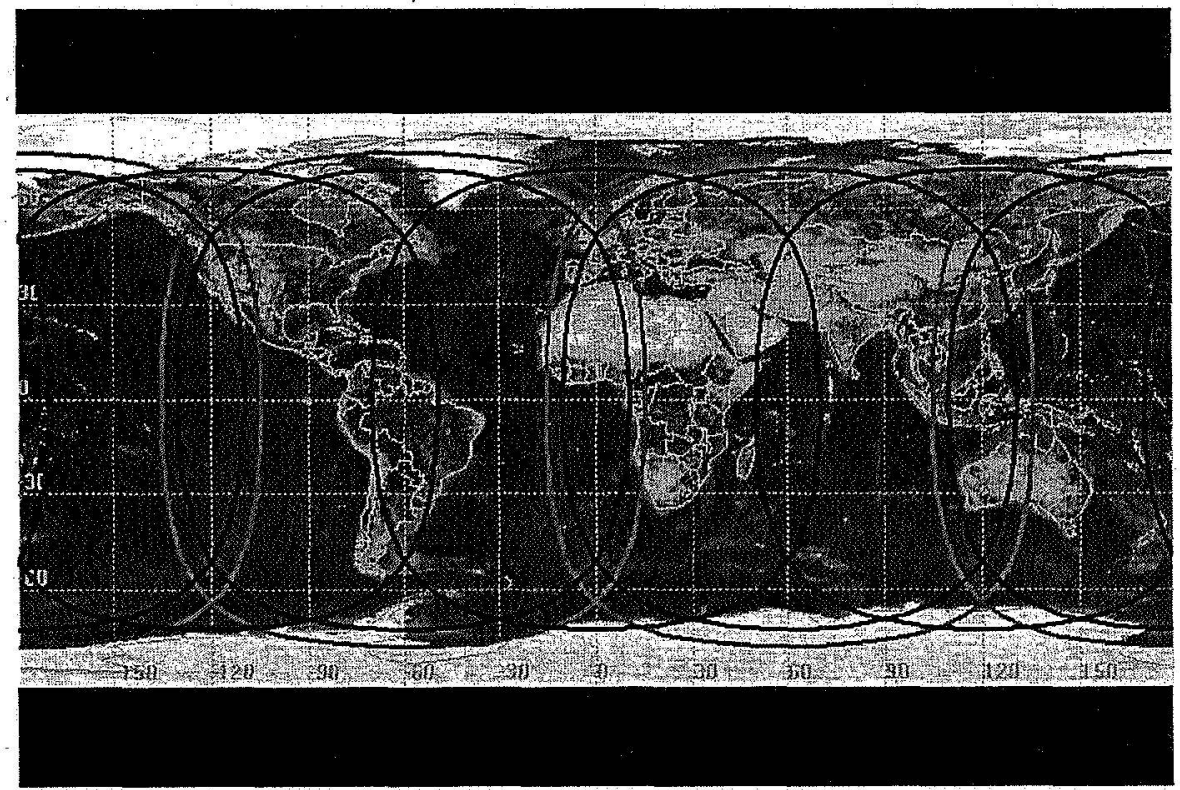

- User services addressed reflect the baseline S-band and Ka-band services, available via the current Space Network (SN), and satisfy the Key Requirements of Table 1.

- For each architecture option, a minimally sized relay constellation -- plus on-orbit sparing -- was assumed that provides global coverage to a surface latitude of at least $\sim 60^{\circ}-70^{\circ}$, with a minimum MA, SA global service complement consistent with that provided by a 3-node constellation of current TDRSS relays. All relays in the constellation were assumed identical, in order to minimize recurring cost. Specific relay quantities, per architecture, are summarized in Table 2 and include 1 or more assumed spares, depending on architecture. 


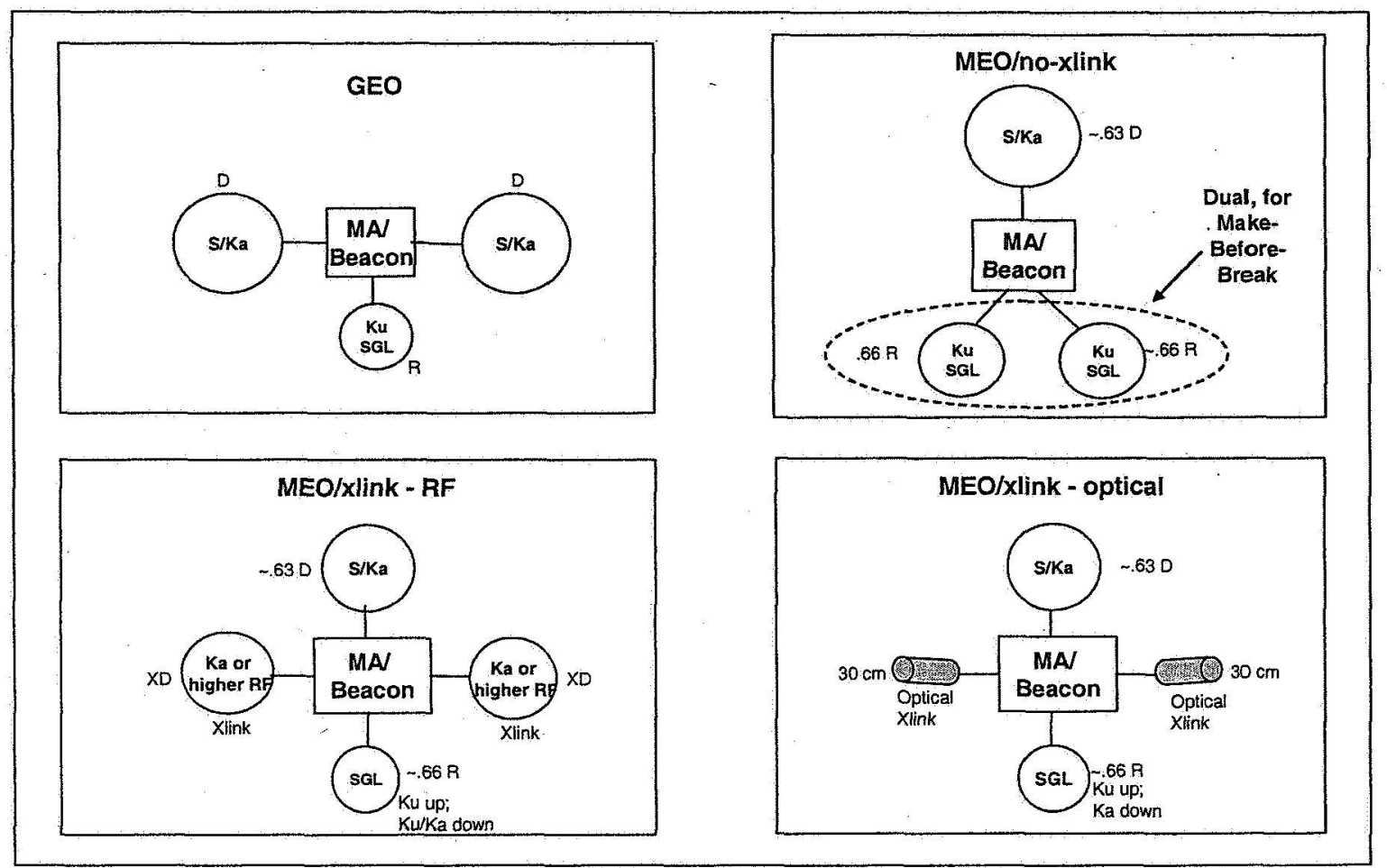

Figure 8: Relay Notional Descriptions

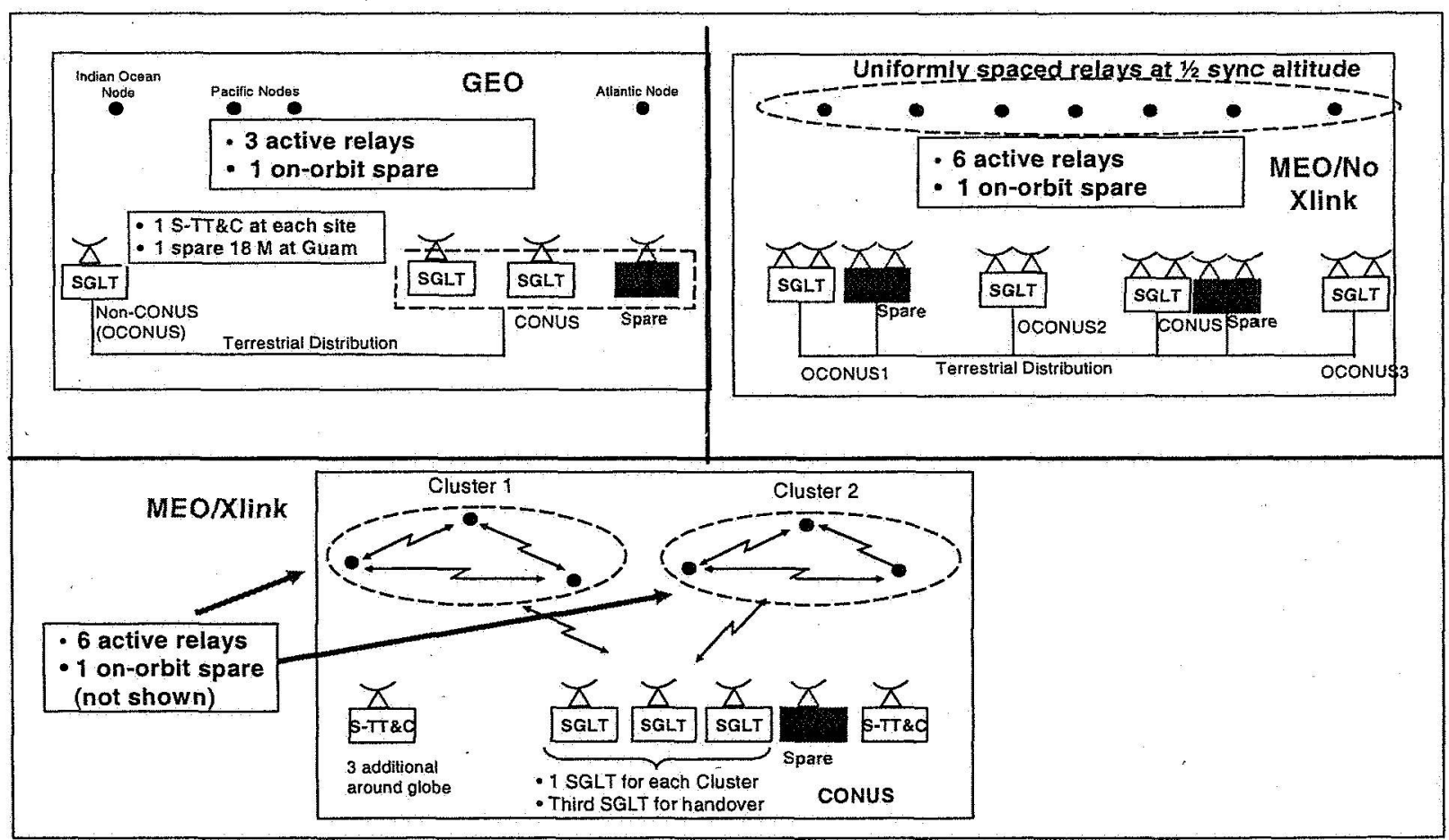

Figure 9: Topologies and High-Level Ground Segment Elements 
- Relays were assumed to be bent-pipe for all non-crosslink architectures, since trades found this to be lower-risk and more cost-effective. For the crosslink scenarios, both RF/bent pipe, and optical/onboard-processed (OBP) were addressed and evaluated.

- The Ground Segment conceptual design was tailored to the specific relay constellation and unique operational aspects, if any. For example, for the GEO constellation, a single ground antenna per relay is required, with very little steering needed due to the nearly stationary satellites. On the other hand, a MEO or LEO constellation requires 2 ground antennas per space/ground link due to relay motion and the need for Make-before-Break operations

Within the above framework, the initial evaluation focused on the GEO, MEO $1 / 2$ sync, and MEO $1 / 4$ sync options indicated in Table 2, and included the additional assumption of a user RF link burden consistent with that provided by the current Space network (SN). This user burden assumption led to the specific sizing of relay service antennas per architecture, with the specific antenna size a function of relay altitude. Conceptual design, sizing and cost estimation led to the relative costs illustrated in Figure 10. For additional insight, the space, ground and launch component relative costs are also included. The following key observations apply:

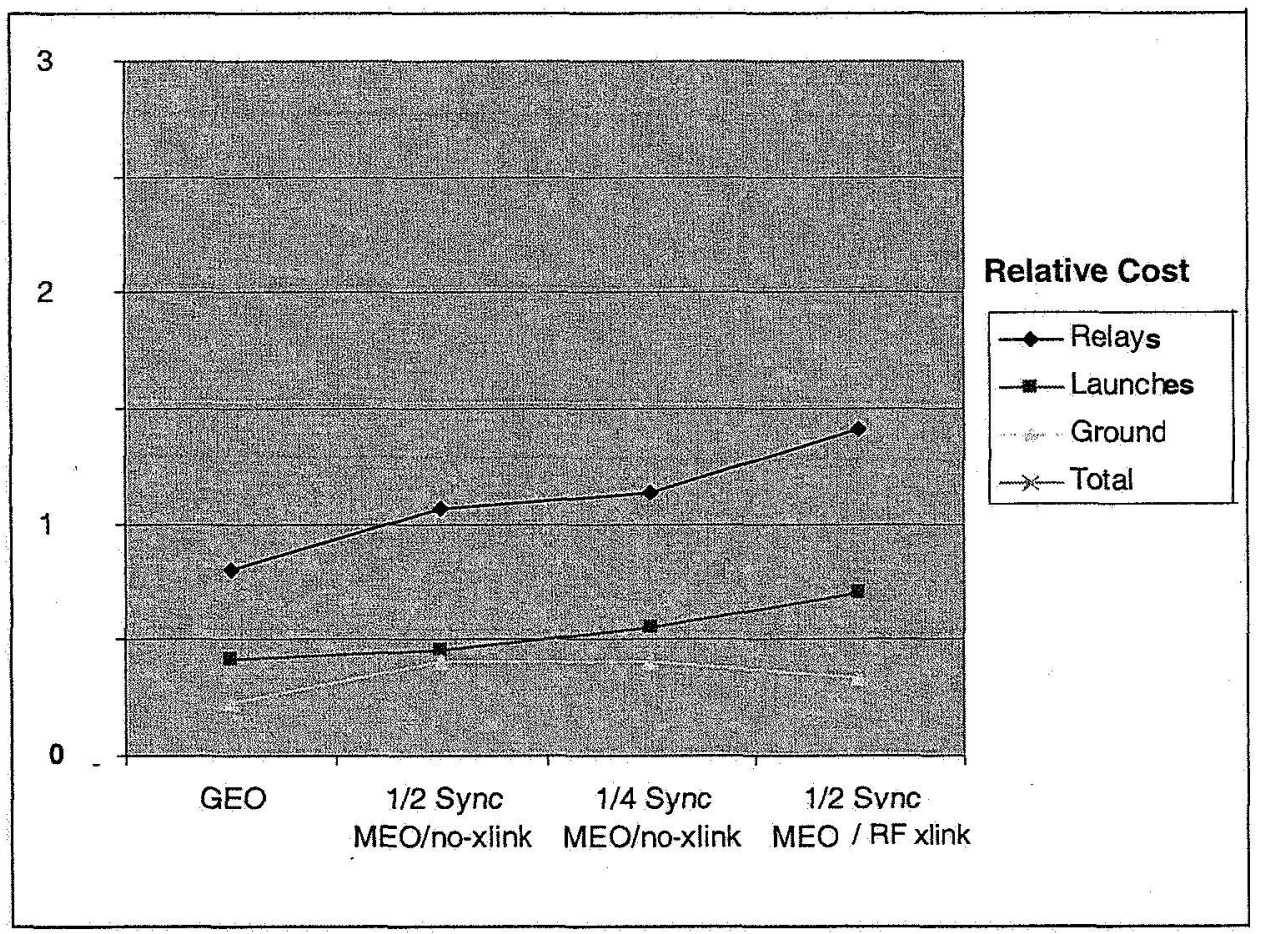

Figure 10: Relative Architecture Costs -- GEO and MEO

- The addition of an inter-relay crosslink into the architecture imposes a considerable cost impact, due to the added relay mass and power required, which directly leads to increased relay and launch cost. 
This crosslink impact on the space segment outweighs the modest ground segment benefit arising from the fewer ground locations needed when the crosslink is present.

- The GEO option, offers the most significant cost benefits, for several reasons:

- Fewer relays must be procured and launched

- No inter-relay crosslink is used

- Fewer ground terminals must be procured than the MEO, non-crosslink options

- The relative costs shown in Figure 10 relate to implementation and launch, but not O\&M. Given that the GEO architecture requires the fewest ground segment locations among all non-crosslink options, it also readily follows that GEO O\&M costs will be lower than its other non-crosslink counterparts. The only non-GEO architecture with fewer ground locations is the MEO $1 / 2$ sync with crosslink; in this case, the lower O\&M associated with only one ground station (and the absence of a need for terrestrial distribution) is much more than offset by the much greater implementation + launch costs.

- In addition to the GEO cost attractiveness, additional figures of merit (FOMs) were addressed. Of the FOMs considered, two stand out as truly being discriminators:

- Operational complexity: Its lower operational complexity was found to highly favor the GEO architecture due to the static nature of the space/ground link. For example, a given ground segment antenna is dedicated to a specific relay on an extended time basis, and is only changed during maintenance or infrequent space/ground link assignment changes. On the other hand, each and every non-GEO architecture requires a more complex make-before-break mode of operation, to accommodate the moving relay constellation.

- Transition: Transition from the current SN to the new NER is greatly simplified via the GEO architecture, given: the continuity in GEO operations; no need to simultaneously operate GEO and non-GEO architectures during a several year transition period; the ability to maintain operations at the same ground locations, with no need for any new Construction of Facilities.

- The above cost and technical considerations are also found to favor the GEO architecture over other lower orbiting relay architectures, such as the $1 / 7$ sync option indicated in Table 2 . As noted, this architecture requires a large number of relays. Also, inter-relay crosslinks are needed, since analysis indicated that this is the only way to reduce the quantity of ground segment locations to a manageable level, which still turns out to be a quantity of four (greater than the two needed for the GEO case). Similar observations apply for the $1000 \mathrm{~km}$ LEO relay architecture shown.

The above cost/technical considerations strongly suggest the attractiveness of a GEO architecture, with the closest contender the MEO $1 / 2$ sync, non-xlink option. This conclusion was further "tested" and validated by addressing "reduced user burden scenarios". Specifically, the following three scenarios were examined and cost estimates obtained:

- Increased service antenna size on GEO -- reduce user burden by $>3.5 \mathrm{~dB}$ 
- Increased service antenna size on MEO $1 / 2$ sync -- equivalent reduction in user burden

- Nominal GEO antenna size employed on $1000 \mathrm{~km}$ LEO -- - $16 \mathrm{~dB}$ reduction in user burden

Cost assessments, analogous to the above, were conducted:

- For the first two cases, the apples-to-apples comparison once again demonstrated the costeffectiveness of the GEO architecture. Here, the cost impacts were primarily incurred due to mass increases in the relay, but the results still highly favored the GEO.

- The latter, $1000 \mathrm{~km}$ case, was addressed in order to gain some feel for what it would take to obtain a truly significant reduction in user burden. It was found that the cost for this benefit is very high. Not only is the number of ground segment locations $(>16)$ and associated operational complexities probably unacceptable, but even if 5 relays are launched at a time, the resulting launch costs are 2.5 times that of the GEO launch costs! These launch costs are above and beyond the much greater cost of procuring the large number of LEO relay spacecraft required.

Based on in-depth technical/cost assessments to date, the GEO architecture appears to be the most attractive NER candidate. 